\title{
əStorm Surge, Blocking, and Cyclones: A Compound Hazards Analysis for the Northeast United States
}

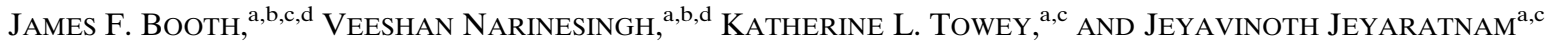 \\ ${ }^{a}$ Department of Earth and Atmospheric Sciences, City College of the City University of New York, New York, New York \\ ${ }^{\mathrm{b}}$ Department of Physics, Graduate Center, City University of New York, New York, New York \\ ${ }^{\mathrm{c}}$ Department of Earth and Environmental Sciences, Graduate Center, City University of New York, New York, New York \\ d NOAA/Center for Earth System Sciences and Remote Sensing Technologies, City College of the City University of New York, \\ New York, New York
}

(Manuscript received 8 April 2021, in final form 29 September 2021)

\begin{abstract}
Storm surge is a weather hazard that can generate dangerous flooding and is not fully understood in terms of timing and atmospheric forcing. Using observations along the northeastern United States, surge is sorted on the basis of duration and intensity to reveal distinct time-evolving behavior. Long-duration surge events slowly recede, whereas strong, short-duration events often involve negative surge in quick succession after the maximum. Using Lagrangian track information, the tropical and extratropical cyclones and atmospheric blocks that generate the surge events are identified. There is a linear correlation between surge duration and surge maximum, and the relationship is stronger for surge caused by extratropical cyclones as compared with those events caused by tropical cyclones. For the extremes based on duration, the shortest-duration strong surge events are caused by tropical cyclones, whereas the longest-duration events are most often caused by extratropical cyclones. At least one-half of long-duration surge events involve anomalously strong atmospheric blocking poleward of the cyclone, whereas strong, short-duration events are most often caused by cyclones in the absence of blocking. The dynamical influence of the blocks leads to slow-moving cyclones that take meandering paths. In contrast, for strong, short-duration events, cyclones travel faster and take a more meridional path. These unique dynamical scenarios provide better insight for interpreting the threat of surge in medium-range forecasts.
\end{abstract}

SIGNIFICANCE STATEMENT: Coastal flooding can be dangerous and expensive, and it is often caused by storm surge. In this study we examine the behavior and causes of storm surge in terms of both surge duration and magnitude. We find that at least one-half of the long-duration surge events are caused by the interactions of cyclones and atmospheric blocking, whereas strong, short-duration surge events are most often caused by cyclones in the absence of blocking. Differences in the time evolution of the surge relate to differences in the cyclones' paths and their interactions with the blocks. These results provide new details on the behavior of storm surge and provide guidance for forecasters when analyzing atmospheric forecasts for their potential to generate surge conditions.

KEYWORDS: Anticyclones; Extratropical cyclones; Storm surges

\section{Introduction}

Coastal flooding due to storm surge can cause dangerous and expensive natural disasters (e.g., Rappaport 2014; Shimkus et al. 2017; NOAA 2021). In a recent survey, emergency support personnel indicated that it would be useful to have additional information about surge characteristics and greater lead times in the forecasts (Munroe et al. 2018). The results of that survey motivate our research in which we analyze characteristics of storm surge events and the atmospheric conditions that generate the events for the northeastern United States.

Previous research indicates that the strongest surge events for the northeastern United States occur most frequently in winter, but they can also occur in autumn and spring (Colle et al. 2010). The events can be generated by tropical cyclones or extratropical

¿ Denotes content that is immediately available upon publication as open access.

Corresponding author: James Booth, jbooth@ccny.cuny.edu cyclones (Zhang et al. 2000; Booth et al. 2016). The property of the atmosphere that is probabilistically most important for surge is the surface wind integrated over approximately one day's time leading up to the surge event (Roberts et al. 2015). When the winds are strong and blowing predominantly toward the west, the surge tends to be strong. In physical terms, for the U.S. East Coast, this would imply a synoptic circulation in which there are tight pressure gradients with lower sea level pressure south of the impact zone and higher sea level pressure to the north. This circulation pattern is what is found using a statistical sorting analysis focused on extratropical cyclones and storm surge (Catalano and Broccoli 2018).

When there are winds blowing inland, if something in the atmosphere slows the northeastward progression of the cyclone generating the surge, then the surge could be sustained for a longer time period, as suggested in an analysis of seasonal surge anomalies (Bernhardt and DeGaetano 2012). For the atmosphere, one phenomenon that is associated with slowing the west-to-east progression of midlatitude weather is blocking. Blocking is defined as the obstruction of the typical midlatitude westerly flow by large, quasi-stationary high pressure 
systems lasting multiple days (Rex 1950). Blocks have been associated with extreme heat and extreme cold (Pfahl and Wernli 2012), as well as extreme precipitation events (e.g., Sousa et al. 2017; Lenggenhager and Martius 2019). For both temperature and precipitation extremes, the dynamical significance of atmospheric blocking is persistence. This same principle should apply to storm surge - as suggested by Catalano and Broccoli (2018) and Bernhardt and DeGaetano (2012). Herein, we expand on those studies by directly analyzing blocking during storm surge events.

For the U.S. East Coast, the path taken by cyclones that interact with blocks often depends on the location of the block (Booth et al. 2017). Thus, if blocking is involved in generating storm surge, the large-scale flow would likely need to be in a specific orientation. If this is the case, there will be additional lead time in the predictability of the surge based on the large-scale flow. Furthermore, when cyclones and blocks interact, the event is categorized as a compound weather hazard. Compound events have recently been analyzed in multiple different contexts (e.g., Wahl et al. 2015; Zscheischler et al. 2018; Catto and Dowdy 2021). In some cases, compound hazards involve multiple simultaneous extremes; in other cases, they involve multiple weather types. In our analysis, we are considering multiple simultaneous weather events that cause a single extreme weather hazard: storm surge.

The remainder of the paper is organized as follows: Section 2 details the datasets and methods used, including our definition of surge duration. Section 3 reports the results, focusing first on the surge characteristics and then moving to an analysis of the atmospheric circulation patterns associated with the surge events. Section 4 discusses the robustness of the results by 1) identifying all compound events involving blocking and cyclones and comparing the characteristics of the events that do and do not cause strong surge and 2) examining the sensitivity of the results to the threshold used in defining surge duration.

\section{Methods}

\section{a. Data}

This study analyzes surge events during all months of the year for the time period from 1950 to 2019 . The starting year corresponds to the starting point of the reanalysis dataset, the European Centre for Medium-Range Weather Forecasts (ECMWF) ERA5 reanalysis (Copernicus Climate Change Service 2017). We carried out the same analysis using a combination of the ECMWF twentieth-century reanalysis (ERA-20C; Hersbach et al. 2015) for 1950-78 and the ECMWF ERA-Interim reanalysis (Dee et al. 2011) for 1979-2018 (the last full year of ERA-Interim). The main results presented were not sensitive to the reanalysis dataset used.

The water-level data used in this analysis are the University of Hawaii Sea Level Center (UHSLC) water-level data (Caldwell et al. 2015). Like all water-level data, the UHSLC data have some gaps. We use the NOAA Center for Operational Oceanographic Products and Services (http://tidesandcurrents.noaa.gov) waterlevel data to fill the gaps, although it still does not result in a completely gap-free time series for any of our study locations. We subtract the predicted tide time series (calculated using the Matlab U-tide harmonic analysis tool) from the observed water-level time series, and the resulting data are the nontidal residual. Next, we remove long-term trends, which are most likely associated with global sea level rise, by calculating and then subtracting a 365-day running mean using the nontidal residual data at each station. As a result, identical to Booth et al. (2016), the primary variable in this study is the hourly storm surge with the long-term trend removed (hereinafter referred to as surge data). Another description for what we call surge is the detrended, nontidal residual.

We note that large storm surge does not always translate to flooding, which also depends on the tide, but storm surge is the most appropriate sea level-related variable for understanding the relationship between atmospheric circulation and flooding potential. However, tides are also known to cause coastal flooding in the absence of storm surge (Hague and Taylor 2021), thus, the events studied herein are not a full representation of all possible flood events for these sites. The stations presented in our analysis are 1) The Battery in New York City, New York (herein, we will refer to this site as NYC); 2) Boston, Massachusetts; 3) Newport, Rhode Island; and 4) Portland, Maine.

\section{b. Cyclone and block information}

For cyclones, Lagrangian track information contains the date and location of the cyclone center. The Lagrangian track information for tropical cyclones is derived from the NOAA Atlantic hurricane database (HURDAT2; Landsea and Franklin 2013). Following the technique of Booth et al. (2016), we consider all tracks in HURDAT2, regardless as to whether they were hurricanes or tropical storms.

We generate the Lagrangian track information for extratropical cyclones by implementing the NASA Modeling Analysis Program (MAP) Climatology for Midlatitude Storminess (MCMS) tracking algorithm (Bauer et al. 2016) on the reanalysis sea level pressure (SLP) field. The reader is referred to Bauer et al. (2016) for full details on the algorithm. We use 6-hourly data for tracking cyclones, because the MCMS algorithm we use is optimized for 6-hourly data. As in Booth et al. (2016), we remove any hurricanes identified by the MCMS algorithm.

For atmospheric blocks, we also generate Lagrangian track information. Unlike for cyclones, for which we only retain the location of the center, for blocks, we also identify all grid points at a snapshot in time that are considered blocked. Thus, we have time-evolving information of blocks, in which we retain all contiguous points involved in the block. Blocks are defined by applying the algorithm of Dunn-Sigouin and Son (2013) to the ERA5 500-hPa geopotential height field (Z500). The algorithm identifies regions that 1 ) are strong, positive anomalies and 2) include a meridional gradient reversal of Z500. Blocks identified in this way must also 1) exceed a specified spatial scale, 2) be quasi-stationary, and 3) last for at least 5 days. The reader is referred to Dunn-Sigouin and Son (2013) for the details of the algorithm. For a given time step, the block tracking algorithm produces a longitude by latitude grid denoting the presence (1) or absence ( 0 ) of atmospheric blocking at each gridpoint. Composites of these grids over a range of 

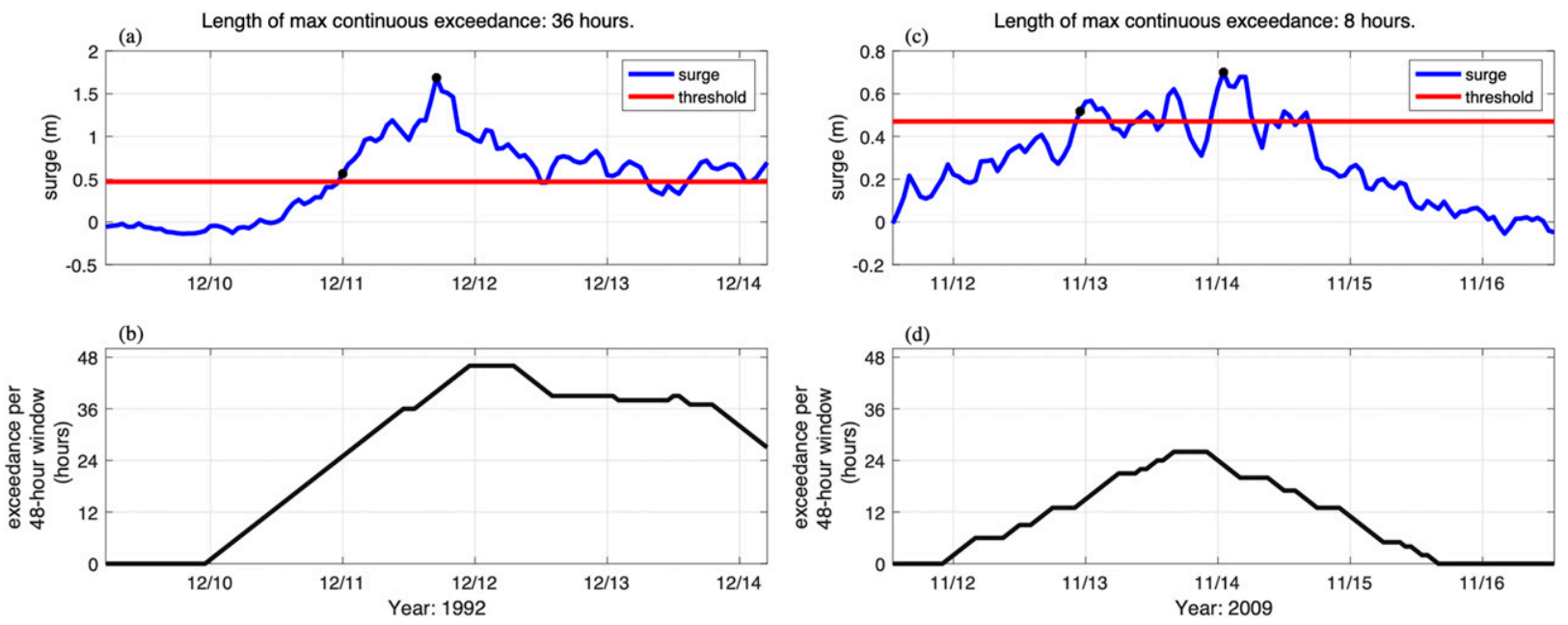

FIG. 1. (top) Surge time series and (bottom) 48-h exceedance duration for two surge examples for NYC: (a),(b) 9-14 Dec 1992 and (c),(d) 11-16 Nov 2009. The red line in (a) and (b) shows the surge threshold ( $S=0.48 \mathrm{~m}$ for NYC) used for defining duration.

time steps yield the blocking frequency, the percentage of time steps a given pixel was identified as being blocked.

\section{c. Identification of surge events}

For each hourly point in the surge time series, we identify the number of hours that surge exceeds a threshold $S$ within a 48-h window centered on the point. This value is calculated for all points in the time series, except the first $24 \mathrm{~h}$ and the final $24 \mathrm{~h}$. The surge threshold $S$ used for identifying the 48-h exceedance durations is defined as the top $1 \%$ of the surge data, per station, and is as follows: for NYC, $S=0.48 \mathrm{~m}$; for Boston, $S=0.40 \mathrm{~m}$; and for Newport and Portland, $S=0.36 \mathrm{~m}$.

The use of $48 \mathrm{~h}$ for our time window is based on two factors. First, we wanted a time scale that was long enough to include multiple tidal cycles. Second, we wanted a time scale that was short enough to most likely correspond to the passage of only a single storm event.

We retain all time stamps for which the 48-h exceedance duration is nonzero, and then we group the intervals that are continuous. For these continuous intervals, we retain the

- maximum 48-h exceedance duration,

- maximum surge within the time interval associated with the maximum 48-h exceedance duration,

- maximum duration of continuous exceedance of the threshold $S$ within the 48 -h window,

- the first date that the surge exceeds the value $S$, and

- date of the maximum surge.

This method is exemplified in Fig. 1 for two cases at NYC. For the case in Figs. $2 a$ and $2 b$, the water level exceeded the threshold of $0.48 \mathrm{~m}$ continuously for $36 \mathrm{~h}$, and the $48-\mathrm{h}$ exceedance duration is $46 \mathrm{~h}$ (the maximum value of the time series shown in Fig. 1b). In case 2 (Figs. 1c,d) the maximum continuous exceedance lasted $8 \mathrm{~h}$, and the 48 -h exceedance was $26 \mathrm{~h}$ (the maximum value of the time series shown in Fig. 1d). Cases such as these motivate our choice to use the 48-h exceedance duration, because it can capture events in which the surge dips below the exceedance threshold for a short time period. It is important to note that any time that the value of the 48-h exceedance duration is nonzero for a continuous interval, we group the event into a single case. Hereinafter, we will refer to the 48-h exceedance duration as the duration.

A final note about surge duration: For NYC, three cases were found to have a continuous exceedance of the $0.48-\mathrm{m}$ threshold for more than 48-h. For these events, the peak surge occurred during the day of 7 March 1962 (The "Ash Wednesday Storm"; the continuous duration of exceedance was $53 \mathrm{~h}$ ), 30 October 2012 ("Superstorm Sandy"; continuous duration: $53 \mathrm{~h}$ ), and 8 March 2018 (continuous duration: 49h). For Boston, there were two cases with a continuous exceedance of $0.4 \mathrm{~m}$ that lasted more than 48h: 12 December 1992 (continuous duration: $52 \mathrm{~h}$ ) and 3 March 2018 (continuous duration: $102 \mathrm{~h}$ ). To our knowledge, these latter two storms have not been given specific names; however, Colle et al. (2008) examined the 1992 event in detail. For Portland, the 3 March 2018 extratropical cyclone generated surge that exceeded the $S=0.36-\mathrm{m}$ threshold for $99 \mathrm{~h}$. For Newport, no event continuously exceeded $0.36 \mathrm{~m}$ for more than $48 \mathrm{~h}$.

\section{d. Associating cyclones and blocks with surge events}

Given the surge-event dates, we use the Lagrangian track data to find the cyclones that generated the surge. Since the cyclone data are 6 hourly, the first step is to round the hourly surge data to the nearest $0000,0600,1200$, or 1800 UTC. Then we identify cyclones for which the cyclone center is located within $800 \mathrm{~km}$ of the surge-event location at $\pm 12 \mathrm{~h}$ of the date of the start of the surge event. The details about search radii for storm surge have been discussed in detail in previous surge analysis (Booth et al. 2016). We note that using a different threshold, such as 500 or $1000 \mathrm{~km}$ does not change the results qualitatively. We confirmed manually that all well-documented surge events were associated with the correct cyclone events. If multiple cyclones were associated with the same surge event, we did the following: 1 ) if one cyclone was a tropical cyclone (TC), we retained both 
the TC and the extratropical cyclone (ETC); 2) if all of the cyclones were ETCs, we retained those that were east of the surge site, or, if none of the ETC met that criterion, we retained the ETC that was closest to the surge-event site.

As with cyclones, this analysis is aimed at determining when there are blocking events that coincide with the surge events. We decided that the most efficient and repeatable method for associating blocking with surge is to identify blocks that occur in a specific region and compare those data with the surge-event time series. Choosing a fixed region in which to identify blocking cases allows us to test for a specific circulation regime, as will be discussed in the results. Therefore, we designated a boxed region spanning $50^{\circ}-60^{\circ} \mathrm{N}$ and $65^{\circ}-80^{\circ} \mathrm{W}$ as the region in which we identify blocks. If more than $70 \%$ of this region contains a pixel identified as being part of a block, based on the Lagrangian definition described above, we designate that time step as blocked. This analysis provides us with a continuous time series with each time step designated as blocked or not blocked. The climatology for blocking frequency in our region of interest is between $3 \%$ and $6 \%$ (Fig. 2). This value is based on all times in the record.

To associate surge events with blocks, we test for a timing overlap between the surge event and blocking. We use a window of time, allowing the block to be present 2 days prior or 2 days after the start date of the surge event. This 4-day window allows for the possibility that a block existed during the buildup to the surge events and/or the idea that the block developed during the surge event. We found qualitatively similar results to those present herein when (i) the block percentage threshold was changed from $70 \%$ to $50 \%$, (ii) the region was modified by $\pm 10^{\circ}$, and (iii) the time overlap between blocking and surge was set to be \pm 1 day.

\section{e. Statistical significance testing}

In one analysis, we consider the linear relationship between surge duration and maximum block strength. For this we examine the statistical significance of the Pearson correlation coefficient using hypothesis testing and Student's $t$ distribution, with the null hypothesis being that the true correlation is zero. The significance level desired is $0.01 \%$. Statistical significance of blocking frequency during the onset of strong surge is calculated using the following Monte Carlo approach:

1) Using all dates from 1950 to 2019 , blocking frequency is composited for a random set of dates equal in length to the number of surge events being examined.

2) This is repeated 1000 times to create an ensemble of blocking frequency composites.

3) A blocking frequency ensemble mean and standard deviation is calculated for each grid point from the ensemble generated in step 2 .

4) A right-tailed $z$ test is employed at each grid point to determine if the blocking frequency during strong surge onset is significantly greater than the ensemble mean. The significance level is set to $0.01 \%$.

Statistical significance for differences in probability distributions are calculated using the two-sample Kolmogorov-Smirnov

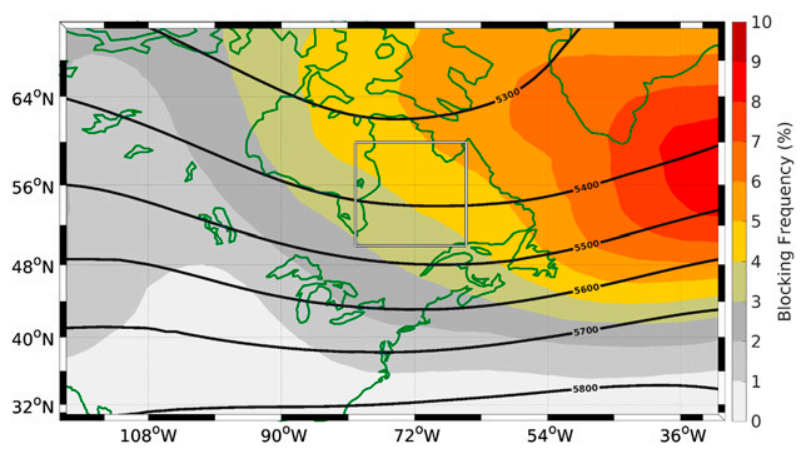

FIG. 2. Annual mean climatology of blocking (shading) and 500-hPa geopotential heights ( $\mathrm{m}$; contours). The white-outlined box indicates the region used in identifying blocks associated with surge events.

goodness-of-fit test with the null hypothesis being that the distributions being compared were drawn from the same population. The significance level desired is again $0.01 \%$.

\section{Results}

\section{a. Surge characteristics}

We analyzed storm surge events in terms of both duration and surge maximum (Fig. 3). For each location, there is a statistically significant correlation between the duration and the maximum surge. For NYC, the Pearson correlation coefficient $r$ is 0.60 . It increases to 0.65 if we consider only extratropical cyclones. For Boston, $r=0.71$ if all cyclone types are considered. For the surge maxima values greater than $1 \mathrm{~m}$, the relationship with duration is noisy and suggests that a processbased relationship between duration and surge maximum can be broken by certain storm surge forcing conditions. This is especially true if we only consider tropical cyclones, as the correlation between duration and surge for events generated by tropical cyclones is weaker than the correlation for events caused by extratropical cyclones. Also note, if we consider only long-duration surge events, the correlation between maximum surge and duration is very weak.

The majority of the events are created by ETCs or some other non-TC disturbance; for example, $93 \%$ of the 602 events for NYC shown in Fig. 3a are ETCs. The number of events that are not associated with a TC or an ETC is 40 . For the analysis presented in Fig. 3, they have been included into the ETC category. For surge duration, there is no clear difference between TCs and ETCs: both types of storms cause a similar distribution of surge durations (Fig. 3). However, the strong surge events with the shortest duration are all TCs (leftmost points in the green-boxed region in all panels of Fig. 3), and the longest duration events are almost all ETCs (rightmost instances in all panels in Fig. 3). This difference may be related to the fact that TCs are more likely to have stronger pressure gradients near their center than ETCs and they are spatially smaller than ETCs. Thus, the TCs can generate very strong winds for a short period of time. Also note, for NYC, at the time of the surge maxima: all six of the TCs that caused 
(a)
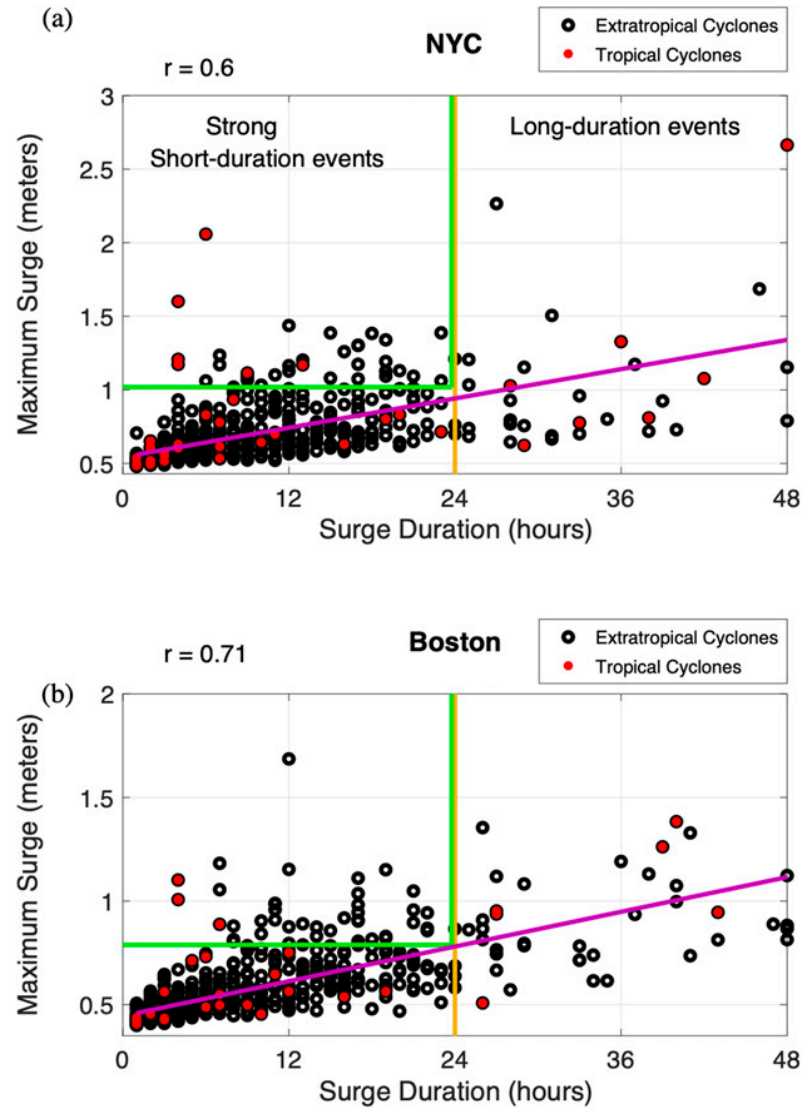

FIG. 3. Surge duration vs surge maximum for (a) NYC and (b) Boston. Duration is defined as the maximum hours exceeding a threshold within a 48-h window, per surge event. Red dots indicate events associated with a tropical cyclone, and black dots indicate those associated with extratropical cyclones. The yellow vertical line at 24-h separates long- and short-duration events. The green-outlined box identifies strong short-duration surge events. The purple line is the linear regression fit. The $r$ value is the correlation coefficient. Thresholds $S$, used for the duration calculation, and $P$, used for defining strong, short-duration surge, are $S=0.48 \mathrm{~m}$ and $P=1.02 \mathrm{~m}$ for NYC and $S=0.40 \mathrm{~m}$ and $P=0.78 \mathrm{~m}$ for Boston.

short-duration surge were still categorized as tropical, whereas four of the six TCs that caused long-duration surge were categorized as extratropical-that is, they had gone through extratropical transition prior to the time of the surge maximum. Related to this: the one outlier long-duration event categorized as a TC in Figs. 3a and 3b is Superstorm Sandy at NYC-which had undergone extratropical transition by the time it made landfall. In terms of surge maximum strength, the probability of tropical cyclones causing large events is much higher-as shown previously for NYC (Orton et al. 2016).

We use our 48-h exceedance duration and separate the surge events into long- and short-duration events, based on a 24-h the threshold (see discussion section for sensitivity tests for this value). Strong, short-duration events are defined as events with a maximum surge larger than a threshold $P$. We define $P$ as the value for which the amount of strong, short-duration surge events is equal to the number of long-duration surge events. For
NYC, $P=1.02 \mathrm{~m}$, which is slightly larger than the $1-\mathrm{yr}$ return period for that site, which equals $0.95 \mathrm{~m}$ (Booth et al. 2016). For Boston, $P=0.78 \mathrm{~m}$, which is equal to Boston's 1-yr return period. This is just a coincidence. The use of a count-based approach for defining this threshold has multiple advantages: 1) it allows us to have equal statistics in comparing the long-duration surge and the strong, short-duration surge events; 2) it allows the method to be applied in an automated fashion at any station that has a sufficient amount of data. We also tested using return periods and top percentiles (e.g., the top $0.05 \%$ ), and the results were always similar.

Centering the events on the time of surge maximum, we generate a composite mean of the storm surge time series for the strong, short-duration and long-duration events (Fig. 4). The strong, short-duration events ramp up and down quickly, while the long-duration events do the opposite. For the strong, shortduration events, the surge level is near zero 1.5 days before the maximum (Fig. 4a), and then often reaches a negative value within $12 \mathrm{~h}$ of its surge maximum. These large negative surge events indicate blowouts, which can also be disruptive to the harbor (Gurumurthy et al. 2019). For Newport and Portland, the results are very similar to those shown for NYC and Boston.

For surge associated with the long-duration events at NYC, 28 of the 34 events are above zero at 1.5 days prior to surge maximum for some of the events and for the multievent average (Fig. 4b), which is perhaps indicative of the longer-time-scale high-water events-as discussed in Bernhardt and DeGaetano (2012). For Boston, 25 of the 42 long-duration events have surge values above 0 at 1.5 days prior to the surge maximum. For both NYC and Boston, the composite mean exceeds the respective threshold for more than $24 \mathrm{~h}$ (Figs. 4b,d). Although the composite means for long-duration are symmetric about their peak surge values, many of the individual events are not symmetric: some events rise gradually and drop quickly, while others rise quickly and then maintain high water over multiple days. None of the long-duration surge events generate large negative surge, and we show that this is related to the characteristics of the cyclones that cause these events.

\section{b. Atmospheric conditions}

As described in the methods section, we use Lagrangian tracks of cyclones and blocks to associate each surge event with the atmospheric phenomena that generated the winds that drove the storm surge event. To introduce this analysis, we examine two cases from NYC: a strong, short-duration surge event that was generated by an extratropical cyclone on 25 October 1980, and a long-duration event, which was also associated with an extratropical cyclone and took place on 13 December 1992 (Fig. 5). For the short-duration event, there is cyclonic wave breaking taking place at the $500-\mathrm{hPa}$ level at the time of the surge event (Fig. 5a). Associated with this wave breaking, there are strong anomalously low geopotential heights above and west (i.e., upstream) of the surge location. This cyclonic anomaly at $500 \mathrm{hPa}$ contributes to the intensification of the surface cyclone (e.g., Holton and Hakim 2013, chapter 7). There are also anomalously high geopotential heights to the northeast (i.e., downstream) of the surge location that are part of the synoptic-scale breaking wave. We also 
(a) Strong, short-duration surge The Battery, NYC

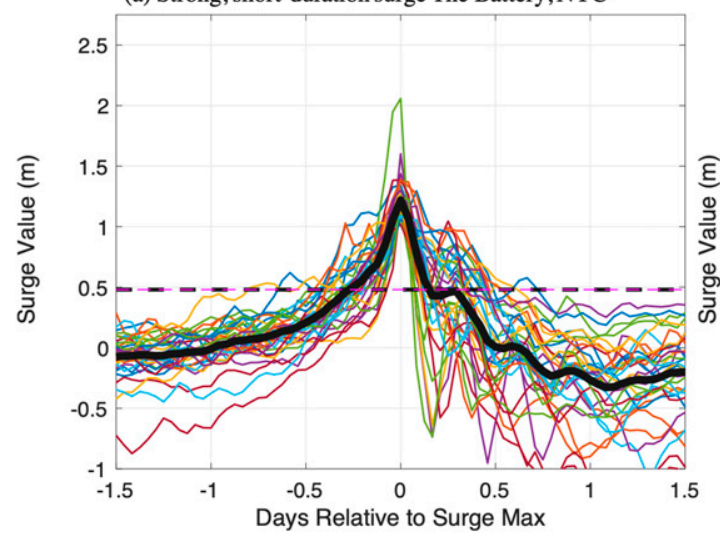

(c) Strong, short-duration surge Boston, MA

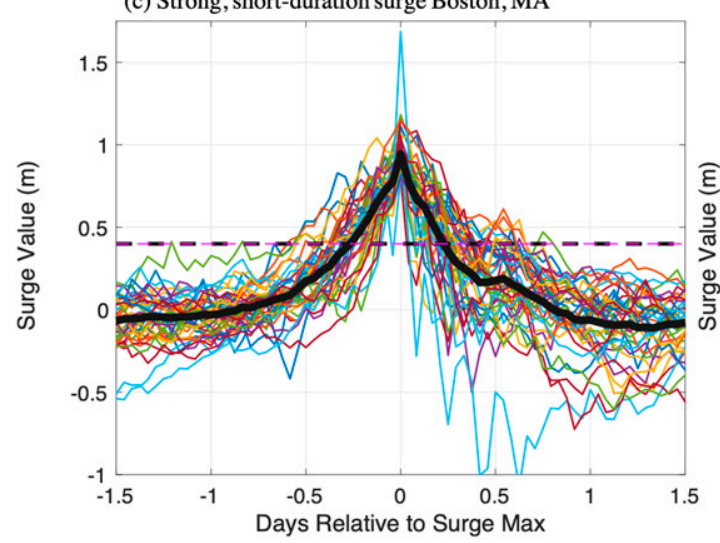

(b) Long-duration surge The Battery, NYC

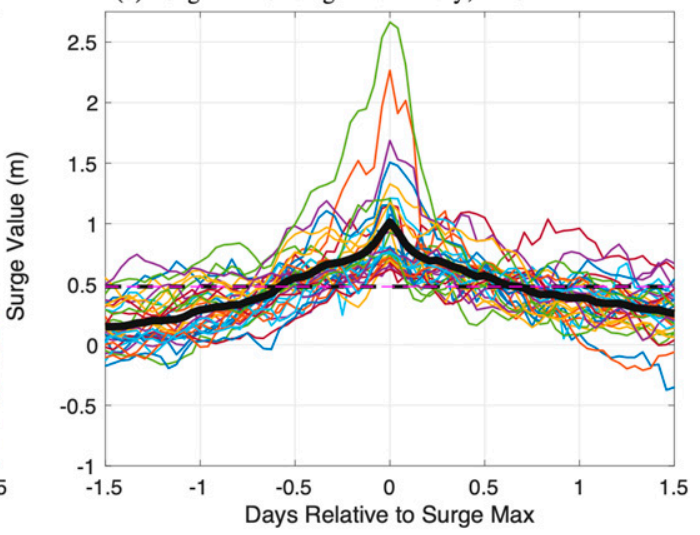

(d) Long-duration surge Boston, MA

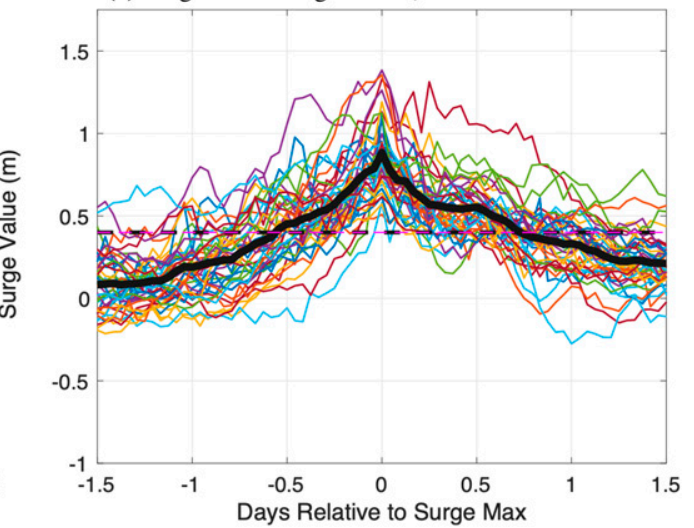

FIG. 4. Time series of storm surge for (left) strong, short-duration events and (right) long-duration events for (a),(b) NYC and (c),(d) Boston. The thick black line represents the multievent average. Thin lines represent each individual event - the same color on two separate panels does not represent the same event. Events are centered on the date of maximum surge. The dashed line shows the threshold $S$ used in defining surge duration. Note that the $y$ axes are not identical for NYC and Boston.

know that these height anomalies do not stay in the same location for very much time, because this region of high heights is not identified as a block. At the surface, there is a deep lowpressure center south of NYC and high pressure to the northeast (Fig. 5b). Thus, the surface and upper-level circulation are very consistent and represent a classic wintertime extratropical cyclone whose development is dominated by the upper-level circulation. This particular cyclone takes a meridional path up the Eastern Seaboard, meaning that the winds at NYC would change from westward to eastward after the cyclone center passed north of the city. This abrupt change in the wind field could allow the surge to quickly recede and become negative, however, more work is needed on understanding the timing of the response of the sea surface to changes in the direction of the winds (see, e.g., Warner et al. 2012).

For the long-duration surge example, the upper-level flow over the northeastern United States and Canada is dominated by anomalously high geopotential heights (Fig. 5c). There is an atmospheric block over most of this region, meaning that the anomalous heights persist in this region for at least 5 days.
South of NYC, the cutoff low in the Z500 field indicates that there is substantial cyclonic, upper-level support for the surface cyclone. However, the persistent anticyclonic flow associated with the poleward block dominates the circulation pattern throughout the region, resulting in a cyclone path that is both meandering and climatologically rare, where the storm moved south as it moved east over the ocean (Fig. 5d). Furthermore, the coaction of the cyclone and the block created strong, persistent onshore winds, which generated the long-duration surge event.

For each location, we determine the number of strong, shortduration and long-duration events, as well as, the number of events that were blocked and the type of cyclone that helped to generate the surge (Table 1). The absolute values are somewhat arbitrary because of the subjective nature of the classification schemes (discussed in detail in section 4); however, the patterns in these numbers are notable.

For all of the locations analyzed, over $70 \%$ of the strong, short-duration surge events did not involve a poleward block. Meanwhile, for the long-duration surge events, at least 50\% did 

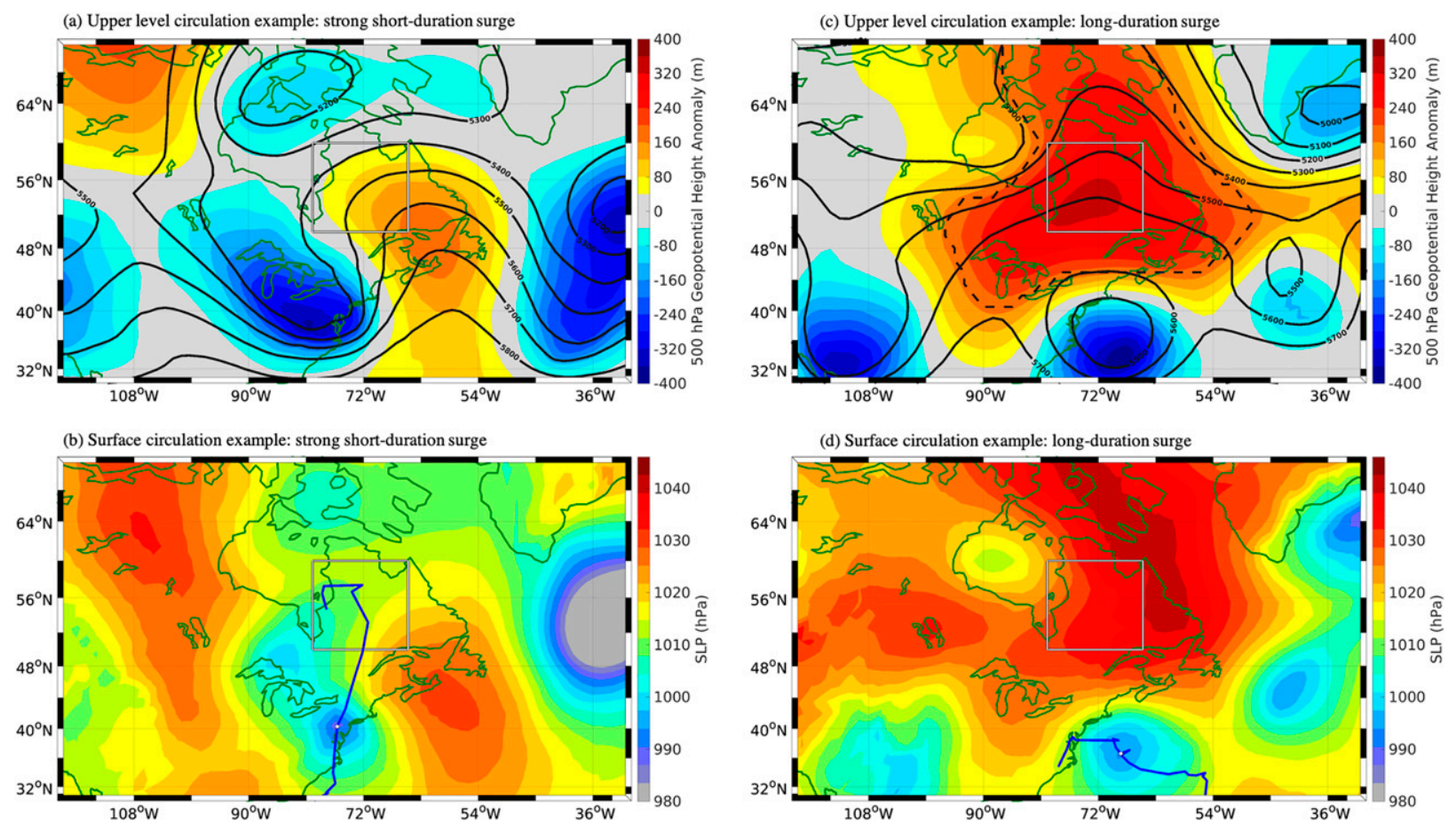

FIG. 5. Upper-level and surface circulation for two surge events, (a),(b) a strong, short-duration surge event on 25 Oct 1980 and (c),(d) a long-duration surge event on 13 Dec 1992. (top) Contours show 500-hPa geopotential heights (Z500), shading shows Z500 anomalies, and the dashed black line in (c) outlines the block location. (bottom) Shading indicates sea level pressure, and the blue line indicates the path of the cyclone. The white dot on the track path indicates location of the cyclone at the time of the snapshot. The white-outlined boxes show the region used for the block association analysis.

involve a poleward block. Given how rarely blocking occurs climatologically $(<10 \%$ of the time), the large amount of blocking during long-duration surge events suggests a physical mechanism and a circulation pattern that is not just due to chance. Furthermore, the long-duration events that do not involve a poleward block often involved positive Z500 height anomalies that migrated east to west (not shown), which is opposite of the behavior observed during strong, short-duration surge events (e.g., Fig. 5).

It is a bit surprising that some of the surge events are not associated with a cyclone or a block (five events at NYC and two events at Boston; Table 1). Therefore, we analyzed the individual SLP and Z500 fields for such cases. Two scenarios were observed: (i) there is a closed low that forms near the surge site, but it dissipates in under $24 \mathrm{~h}$, which means it would not be retained by the extratropical cyclone tracking algorithm; (ii) there is a notable, mobile, high pressure system but no cyclone within the search radius. For these events, it might be related to interactions of tides and gravity waves, or it might also be the case that other ocean conditions were most important for driving the surge event.

To visualize the most likely circulation pattern that sets up for the different types of surge events, we use composite analysis. For this, we consider all of the surge events that are classified as strong, short-duration and long-duration. As with the case studies, the composites shown in Fig. 6 are for NYC, however, similar circulation patterns exist for Newport,
Boston, and Portland. For the strong, short-duration cases, the upper-level circulation shows a pairing of positive and negative height anomalies along a southeast-to-northeast axis, and the negative anomaly is stronger in the composite mean (Fig. 6a). At the surface, the SLP contours in the composite indicate the high probability of a strong cyclone

TABLE 1. Counts of storm surge events and the associated atmospheric conditions [i.e., tropical cyclone (TC), extratropical cyclone (ETC), or no cyclone found within $800 \mathrm{~km}$ of the location ("neither") using the track identification algorithm], stratified by duration of surge and presence/absence of blocking.

\begin{tabular}{|c|c|c|c|c|c|c|}
\hline \multicolumn{3}{|c|}{ Blocked } & \multicolumn{4}{|c|}{ Not blocked } \\
\hline $\mathrm{TC}$ & ETC & Neither & $\mathrm{TC}$ & ETC & Both & Neither \\
\hline \multicolumn{7}{|c|}{$\begin{array}{l}\text { Strong, short-duration surge at NYC } \\
(n=34: 9 \text { blocked and } 25 \text { not blocked })\end{array}$} \\
\hline 1 & 8 & 0 & 5 & 20 & 0 & 0 \\
\hline \multicolumn{7}{|c|}{$\begin{array}{l}\text { Long-duration surge at NYC }(n=34: 21 \text { blocked and } 13 \text { not } \\
\text { blocked })\end{array}$} \\
\hline 3 & 15 & 3 & 2 & 8 & 1 & 2 \\
\hline \multicolumn{7}{|c|}{$\begin{array}{l}\text { Strong, short-duration surge at Boston } \\
(n=42: 8 \text { blocked and } 34 \text { not blocked })\end{array}$} \\
\hline 0 & 8 & 0 & 2 & 31 & 1 & 0 \\
\hline \multicolumn{7}{|c|}{$\begin{array}{l}\text { Long-duration surge at Boston } \\
(n=42: 21 \text { blocked and } 21 \text { not blocked })\end{array}$} \\
\hline 2 & 18 & 1 & 3 & 16 & 1 & 1 \\
\hline
\end{tabular}



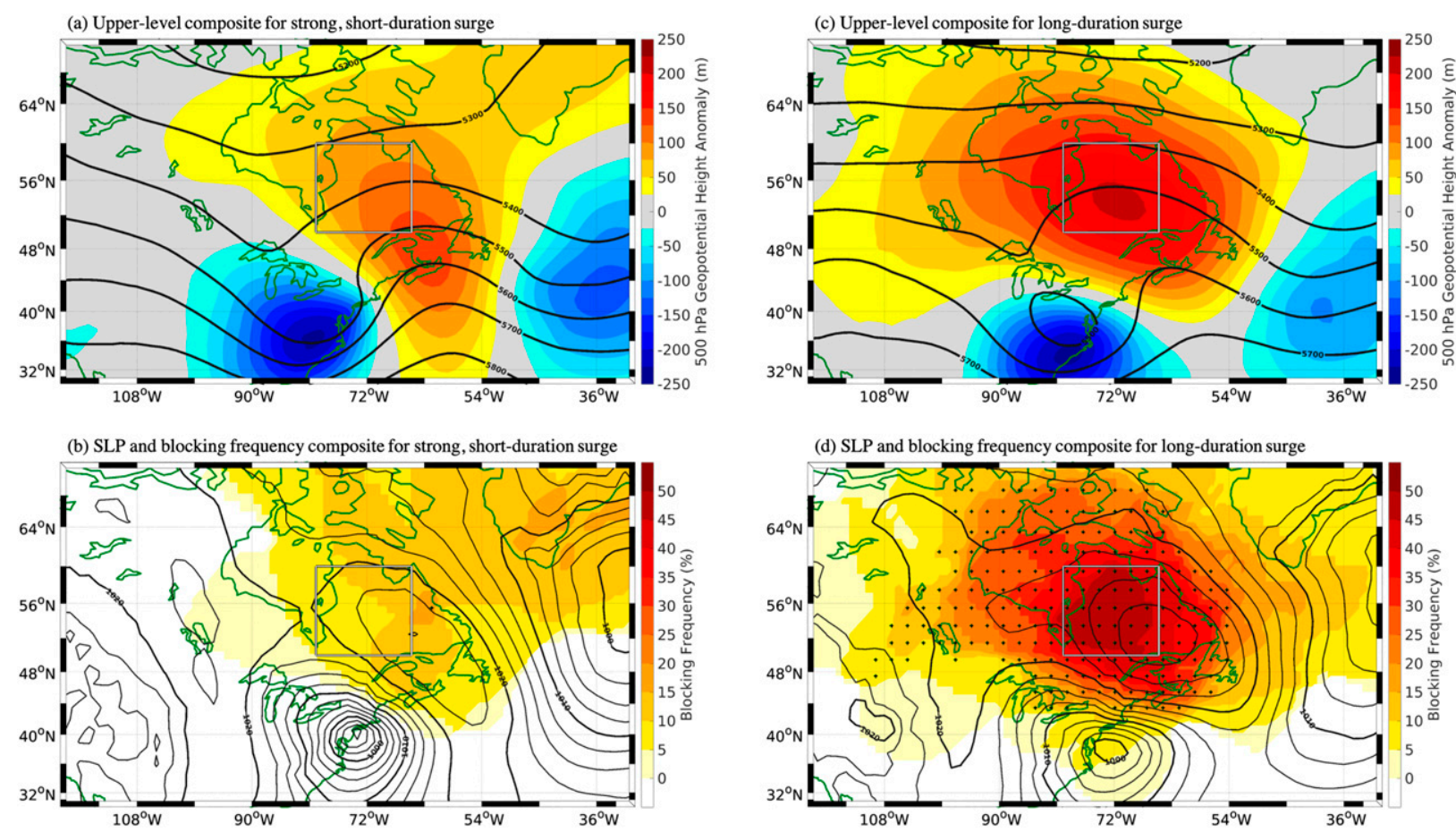

FIG. 6. Composite mean circulation for (a),(b) strong, short-duration surge and (c),(d) long-duration surge for NYC. (top) Contours show 500-hPa geopotential height, and shading shows anomalies. (bottom) Shading shows blocking frequency, and contours show sea level pressure (hPa). Stippling in (d) shows regions where blocking amount in the composite is significantly larger than in the climatology. For both cases, the composites use the start dates of the surge events. The white-outlined boxes show the region used for the block association analysis. White regions in (b) and (d) have zero blocking frequency-there are no negative values.

occurring in close proximity to the surge location (Fig. 6b). There are some instances of poleward blocking; however, the frequency is never larger than $20 \%$. For the long-duration surge, there is also a pairing of negative and positive height anomalies (Fig. 6c); however, the orientation of the anomalies is closer to a north-south alignment. At the surface, SLP shows a similar pattern (Fig. 6d), and there is a significantly large value for blocking frequency poleward of the surge location. This compositing analysis emphasizes the important dynamical differences in atmospheric conditions that generate short- and long-duration surge: the presence of a block or blocklike conditions for longduration surge, and the concentrated strength of the surface cyclone for the strong, short-duration surge.

Next, we focus on the track paths of the strong, short-duration cyclones and the long-duration surge events (Fig. 7). For both NYC and Boston, the short-duration events often involve cyclones that take a southwest-to-northeast path over the surge location. The cyclone centers often pass very close to the surgeevent location, with only a few exceptions (Figs. 7a,c). As was shown in the case study, many of the events travel northward as they pass over NYC and Boston, and this results in strong eastward winds after the cyclone center passes over the surge location. These winds would push the water away from the shore (e.g., Gurumurthy et al. 2019), and this is what is observed in the surge time series (Figs. 4a,c). For long-duration surge, the tracks are more zonal and often contain abrupt turns (Figs. 6b,d). Critically, almost none of the tracks pass due north over the surge location. As seen in the case study, this can relate to the presence of a block poleward of the location of the surge. Tracks for Newport and Portland are not shown because they look so similar to NYC and Boston.

We quantify differences in the cyclone characteristics by comparing the cyclone details at the time that they cause the surge. For this analysis, we consider five categories: 1) all cyclones that pass within $800 \mathrm{~km}$ of the surge location (the same search distance used for the cyclone associated analysis), 2) cyclones that generate strong, short-duration surge in the absence of blocking, 3) cyclones that cause strong, short-duration events during a poleward blocking event, 4) cyclones that cause longduration surge with no poleward blocking, and 5) cyclones that cause long-duration surge during a poleward blocking event.

The first detail we analyze is cyclone track speed, that is, the speed of movement of the cyclone center. Track speed is calculated using a window of $24 \mathrm{~h}$ centered on the time when the cyclone is closest to the location of the surge. For this metric, only the cyclones that created long-duration surge in the presence of a poleward block differ significantly from the full set: they are slower (Fig. 8a, magenta curve). The presence of blocking is clearly associated with this decrease in the track speeds as the other set with a distribution that is shifted toward slower values includes the cyclones that cause strong, short-duration surge in the presence of a poleward block (Fig. 8a, orange curve).

The tracks shown in Fig. 7 indicate that the cyclone tracks that create long-duration surge during a poleward block event tend 

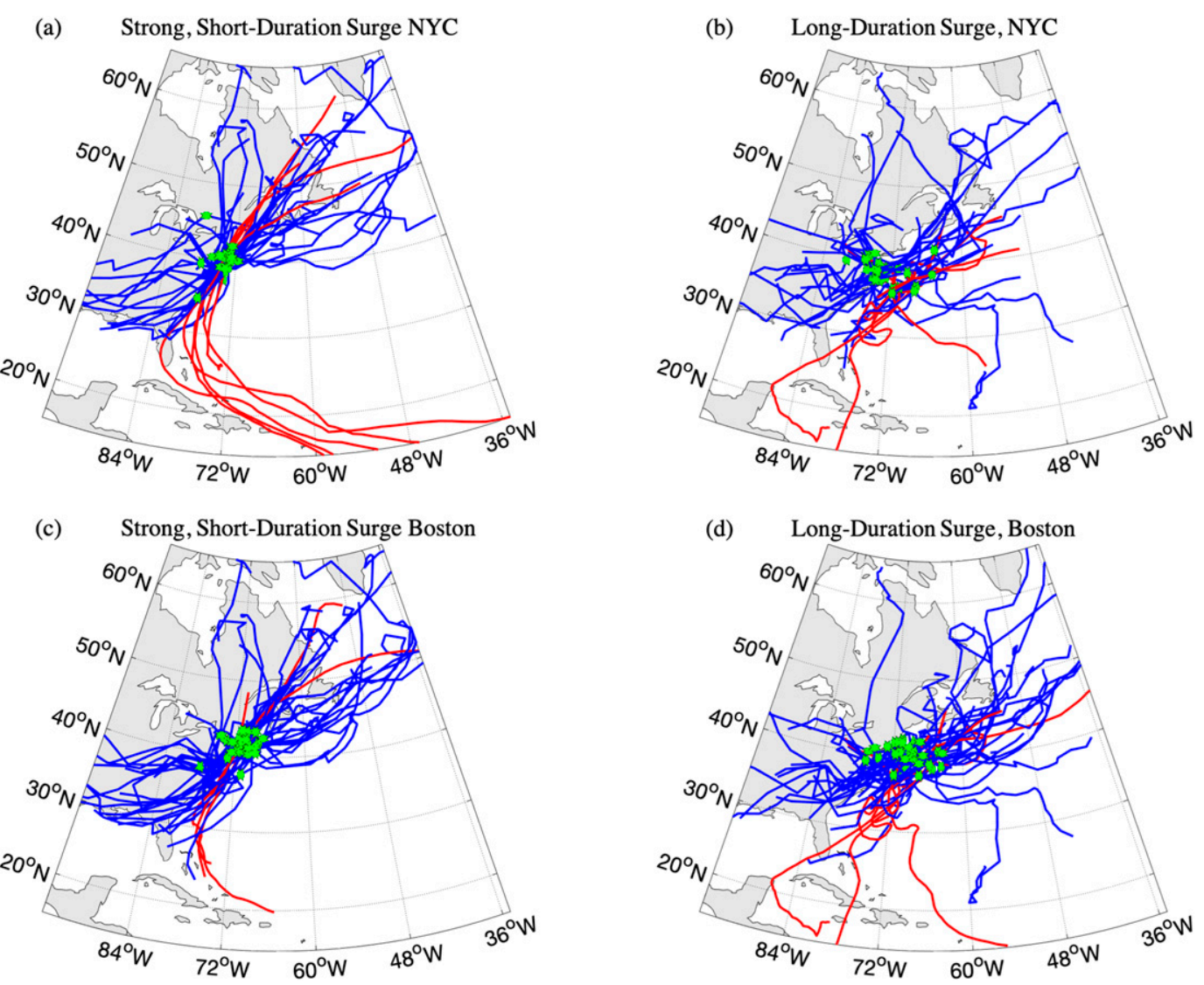

FIG. 7. Tropical (red) and extratropical (blue) cyclone track paths that generated (left) strong, short-duration surge, and (right) long-duration surge, shown for (a),(b) NYC and (c),(d) Boston. Green circles indicate the location of the cyclone at the time of maximum surge.

to meander more than those that cause short-duration surge. To quantify this, we define the average change in track angle:

$\Delta \operatorname{TrackAngle}(t)=\sum_{t-4}^{t+4} \Delta \theta^{*}(t), \quad$ where

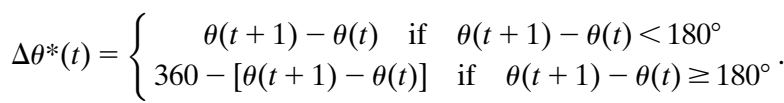

Tracks with a large $\Delta$ TrackAngle are those that switch directions frequently, whereas those with a small $\Delta$ TrackAngle tend to follow a linear path. Note that this metric says nothing about which direction the tracks take; instead, it measures how much the track direction changes. The conditional definition of $\Delta \theta^{*}(t)$ accounts for the discontinuity in angles at the boundary between $0^{\circ}$ and $360^{\circ}$. Using this metric, we find that the cyclone tracks associated with long-duration surge are much more likely to have large average track angles, regardless of whether there is a poleward block (Fig. 8b, blue and magenta curves). On the other hand, the tracks that generate strong, slow surge events tend to be straighter than the full set of cyclones. These distributions differ significantly from that of the full set of cyclones.

Next, we examine cyclone strength using central SLP minimum when the cyclone is closest to the location of the surge event. Cyclones that cause strong, short-duration surge and those that cause long-duration surge tend to be stronger than the full set of cyclones. In both cases, the distributions are significantly different from the full set (Fig. 8c). The storms that cause strong, short-duration surge are stronger than those that cause long-duration surge at NYC (lines with dots vs those without), these strength differences are even larger for Newport, Boston, and Portland (not shown). The results for track speed, $\Delta$ Track Angle, and SLP have been shown for NYC; however, similar results hold for Portland, Newport, and Boston-with the exceptions that were already mentioned.

To summarize the results represented in Figs. 7 and 8: a cyclone that causes strong, short-duration events tends to take a direct, southwest-to-northeast path, and have a deep central pressure. In contrast, the most likely characteristics of a cyclone that causes long-duration surge are slow movement, multiple changes in track path direction, and a deep central pressure.

\section{Discussion}

\section{a. Blocking and cyclone events without long-duration surge}

In terms of weather hazard prediction, our finding that the coaction of blocking and cyclones generates long-duration surge events is potentially useful. However, up to this point 
(a) Cyclone Track Speed

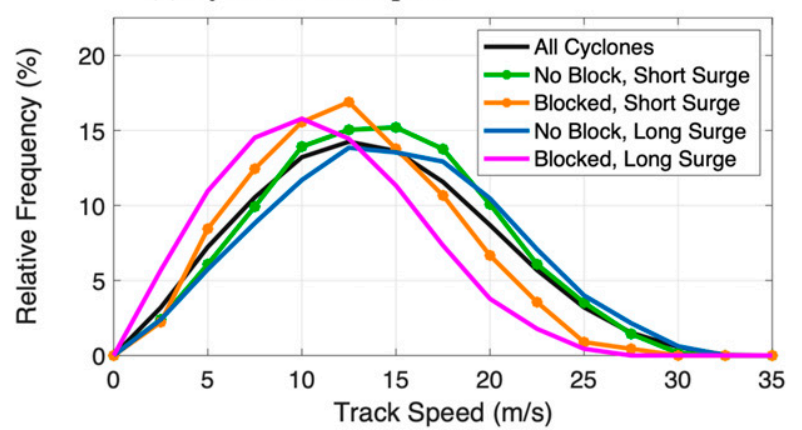

(b) Cyclone Track Meander

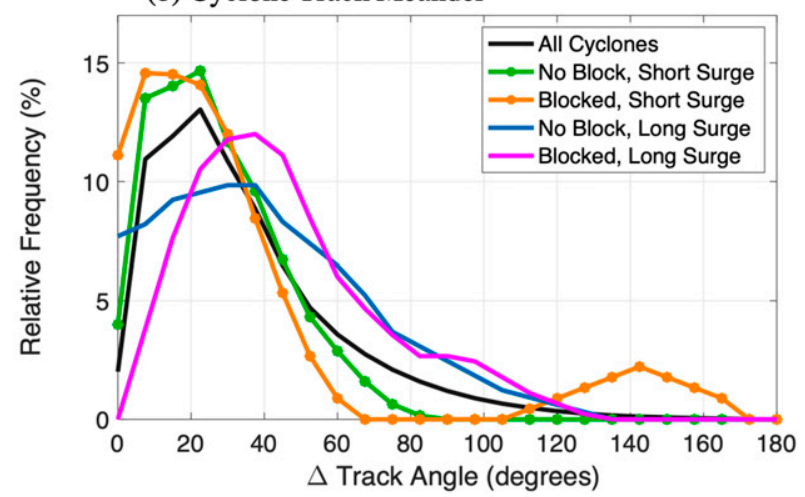

(c) Cyclone Strength

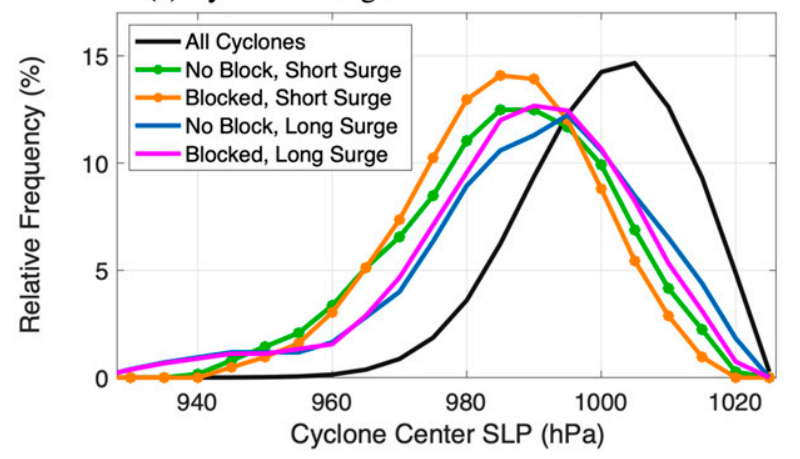

FIG. 8. Relative frequency distributions of cyclone characteristics causing surge at NYC, giving comparisons of all cyclones within $800 \mathrm{~km}$ of NYC (black), cyclones that generated strong, shortduration surge with no poleward block (green with dot) or with a poleward block (orange with dot), and cyclones that generated long-duration surge with no poleward block (blue) or with a poleward block (magenta). Shown are (a) track speed, (b) average change in track angle-our measure of how much the track meanders, and (c) the cyclone's central sea level pressure minimum at the time of maximum surge.

our analysis has only considered dates on which a strong, shortduration or long-duration surge event occurred. To better contextualize this relationship, we need to consider all cases in which a poleward block occurred at the same time that a cyclone passed within close proximity of the surge location. Therefore, we identified all dates in which a poleward block occurred, and then for those events we found the subset for which a cyclone passes within $800 \mathrm{~km}$ of the location of the surge. Our sensitivity tests found little to no change if we use a value of 1000 or $400 \mathrm{~km}$ for this search radius (not shown).

For NYC, the set of blocking-plus-cyclone events can then be separated into the 21 long-duration surge events and 69 cases in which there is blocking and a cyclone close, but no long-duration surge. Figure 9 compares the distributions of block strength, cyclone strength, and surge strength for these two scenarios. For long-duration surge events, the blocks and cyclones are stronger (Figs. 9a,b). The difference in maximum surge strength (Fig. 9c) indicates that the cases that do not qualify as long-duration surge events tend to be weak surge events. Interestingly, there was only a small difference in the distributions of track speed for these two cyclone categories (not shown). Thus, the take-home message from this analysis is the coaction of blocking and cyclones can lead to extreme storm surge; however, such a scenario is much more likely if the block and the cyclone are both strong.

\section{b. Sensitivity analysis for duration}

One key result of our analysis is the finding that at least half of the long-duration events are associated with poleward blocking. However, our definition of long-duration surge is based on a 24-h threshold, which is clearly subjective. Therefore, we also analyzed the sensitivity of our results to this threshold, letting it range hourly from $6 \mathrm{~h}$ up to $36 \mathrm{~h}$. Then for each duration threshold we identified the long-duration surge events. For each set of events, we identified the percentage of events associated with a poleward block. The results are presented in Fig. 10.

For the four sites analyzed for this paper, the percentage of long-duration events associated with blocks is around $30 \%$ if we define the events using a 6-h threshold (Fig. 10). Given that the climatological blocking frequency is $4 \%-6 \%$ (Fig. 2), it is clear that the occurrence of blocking during persistent longduration surge events is not a coincidence. Furthermore, as we require a longer duration for our definition of long-duration surge, the percentage of events associated with blocking steadily grows. For NYC and Newport, the percentages top off near $80 \%$. For Boston and Portland, the percentages top off around $60 \%$. These differences are likely due to details about the orientations and bathymetry of the ocean and bay in the vicinity of each location. This issue is a topic for our future work. However, this should not distract from the significant result that strong, poleward blocks often generate persistent surge for the U.S. Northeast.

\section{c. Cyclones impacting multiple locations}

Next, we determine the number of cyclones that generated strong, short-duration or long-duration surge events at two of the study sites. Hereinafter, we will refer to these as overlapping events. Table 2 provides the results, separated by cyclone type. On the table, sites are listed geographically, moving from the location that is the farthest south (NYC) to the location that is the farthest north (Portland). The results are also separated by surge type, with overlapping short-duration event counts given in the lower triangle of the matrix and overlapping counts for long-duration events given in the upper triangle of 

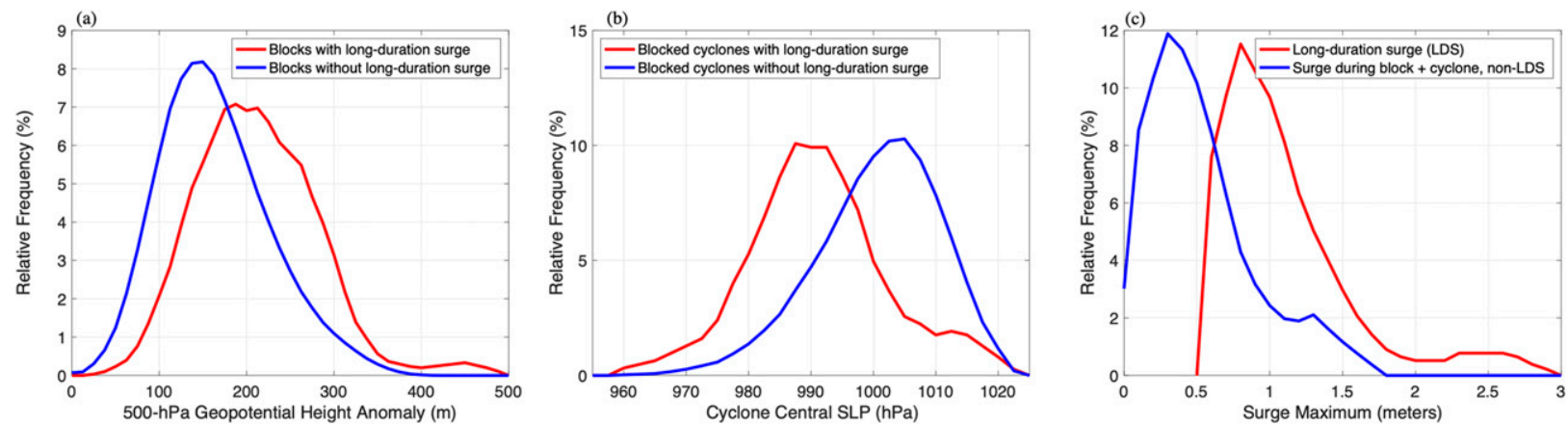

FIG. 9. Relative frequency distributions focused on dates with poleward blocking, comparing long-duration surge (LDS) events (red) and non-LDS events (blue): (a) blocking strength (larger anomaly = stronger block), defined as the area average of the Z500 height anomaly for the box-outlined region in Fig. 2, (b) central sea level pressure minimum (lower pressure $=$ stronger storm) for extratropical cyclones that pass within $800 \mathrm{~km}$ of NYC when a poleward block is present, and (c) surge maximum. For non-LDS events, this value is the maximum surge for a 2-day window centered on the time when the cyclone passes closest to NYC.

the matrix. For example, extratropical cyclones generated 25 short-duration events at NYC, and 9 of those cyclones also created a short-duration event at Newport.

For extratropical cyclones, there are similar numbers of overlapping events for both surge types. The counts are around 10 per city combination, with one exception: the combination of NYC and Portland. For long-duration surge, the number of overlapping events between two cities decreases as the distance between the locations increases. In contrast, for strong, short-duration events the numbers are closer to constant with respect to distance between pairs of sites. This perhaps reflects the fact that the paths of the cyclones causing these events are very similar to the orientation of the coastline.

The relative number of tropical cyclones that cause overlapping events is as large or larger than that for extratropical cyclones. The tropical cyclones involved in all of the longduration overlapping events are "Superstorm Sandy" and the "Perfect Storm" of October 1991. Both of these events are (a) The Battery, NYC

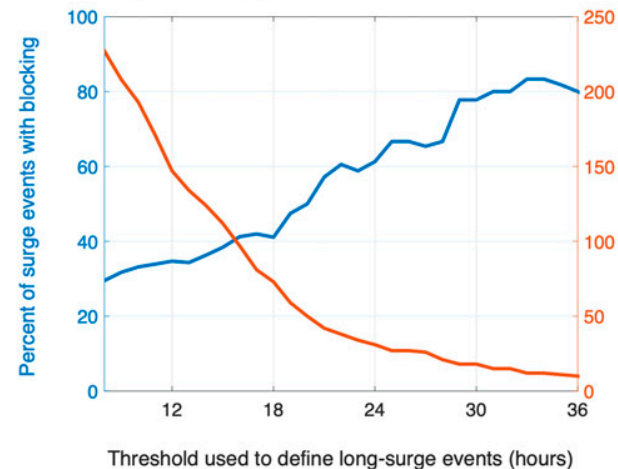

(c) Boston, MA

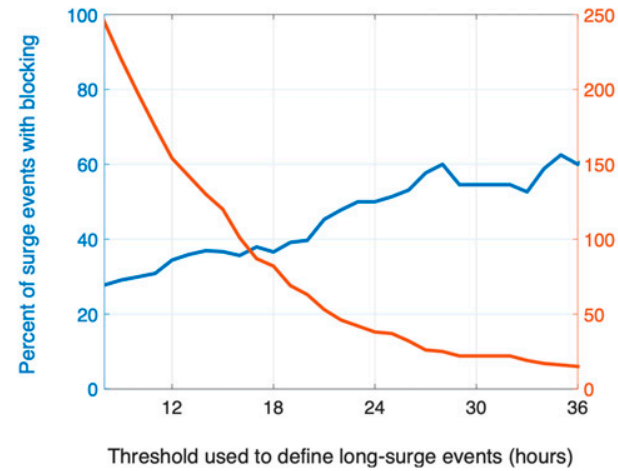

(b) Newport, RI
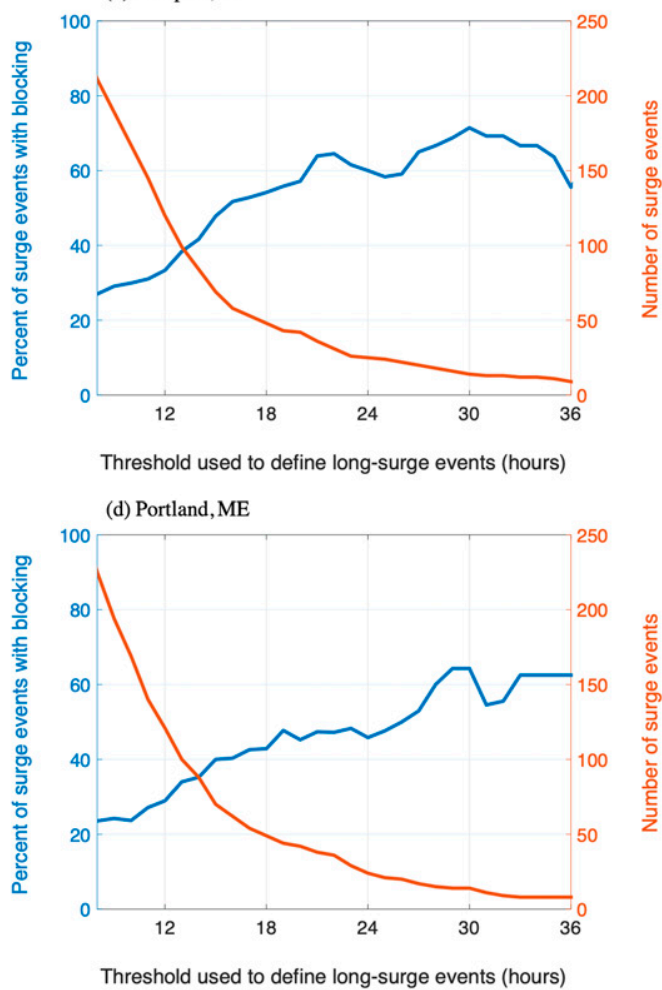

FIG. 10. Block frequency (blue) and number (red orange) of long-duration events as a function of the threshold used to define long-duration surge for (a) NYC, (b) Newport, (c) Boston, and (d) Portland. 
TABLE 2. Analysis of cyclones that caused surge event at pairs of cities. Values in the lower left of each section of the table are counts of cyclones that causes strong, short-duration surge at the cities listed for the corresponding column and row. Values in the upper right of each section of the table are for cyclones causing longduration surge per city listed in each corresponding column and row. Values along the diagonal are the counts of total events per city, again split by surge type, as described above. Values in parentheses are cases that are strong, short duration at one location and long duration at the other location.

\begin{tabular}{lrccc}
\hline \hline & NYC & Newport & Boston & Portland \\
\hline NYC & $\left.28\right|^{24}$ & 10 & $7(5)$ & $4(2)$ \\
Newport & 9 & $\left.24\right|^{21}$ & $12(4)$ & 9 \\
Boston & 10 & 11 & $400^{35}$ & 15 \\
Portland & 7 & 11 & 10 & $\left.24\right|^{26}$ \\
NYC & $61^{6}$ & Tropical cyclones & & \\
Newport & 2 & $\left.3\right|^{2}$ & $2(1)$ & 2 \\
Boston & 0 & 1 & $\left.3\right|^{6}$ & $2(3)$ \\
Portland & 0 & 0 & 2 & $31^{2}$ \\
\hline
\end{tabular}

notable for their size, caused by the merging of the tropical cyclone with a well-developed midlatitude storm. For tropical cyclones that generate strong, short-duration events, there are no overlapping events between cities that are not adjacent (based on our list). This is likely related to these events involving cyclones that are smaller in horizontal scale than the rest of the cyclones analyzed for this study.

\section{d. Antecedent conditions for long-duration surge events}

Here we report on the upper-level atmospheric circulation for long-duration surge events. This section serves two purposes in which 1) we will show the atmospheric conditions leading up to the surge maximum for the long-duration surge events, and 2) we discuss the differences in the upper-level circulation for blocked and not-blocked long-duration surge events. For this analysis, we choose to show the composites for the Boston events, because there are an equal number of blocked and not-blocked cases. However, the results are very similar for NYC.

Three days prior to the maximum in surge, for long-duration events that are blocked, there is already an anticyclonic anomaly at $500 \mathrm{hPa}$ over most of eastern Canada (Fig. 11a). Related to this anticyclonic anomaly, in $50 \%$ of the events, the region is already occupied by a block (not shown). For longduration surge events that are not blocked, there is also an anticyclonic anomaly over eastern Canada. However, it is weaker, spatially smaller and positioned farther west than the anticyclonic anomaly in the case of blocked long-duration surge events. At three days prior to the surge maximum, there is also very little blocking detected in the not-blocked cases (not shown). Moving forward in time, to two days and one day prior to the surge maximum, the strength of the anticyclonic anomalies strengthen for both the blocked and not-blocked cases. On the date of the surge maxima for the long-duration events, the anticyclonic Z500 anomalies reach their peak strength for both the blocked and not-blocked cases (Figs. 11c,d). The anomaly is 2 times as strong in the blocked case ( $\sim 250 \mathrm{vs} \sim 125 \mathrm{~m}$ at the center of the anomaly). The full Z500 field (contoured in Fig. 11) shows that, for the blocked cases, anticyclonic wave breaking is even visible in the composite mean (despite averaging over multiple cases in which the exact positions of the blocks differ). During the three days following the surge maximum, the anticyclonic anomalies weaken for both the blocked and the notblocked cases (not shown) but those for the not-blocked cases weaken more quickly, such that, by day +3 , the differences in the anomalies look similar to the differences shown for three days prior (i.e., Figs. 11a,b).

These results indicate that for one-half of the long-duration surge events the atmospheric circulation leading up to the event can serve as an indicator for the potential for longduration surge events. Also, for the not-blocked events, a poleward anticyclone occurs and has a role to play in generating the strong pressure gradients that produce the winds that create the surge. However, the persistence of the anomaly is much weaker in the not-blocked cases as compared with the blocked cases.

\section{Conclusions}

The coaction of the blocks and the cyclones is indicative of a compound weather hazard, and in this study, we found that their interactions can impact storm surge duration. Strong, short-duration surge events are usually driven by cyclones in the absence of poleward blocking. These surge events include both a fast increase and decrease in the water level, leading to negative surge levels that could be consequential. On the other hand, the long-duration surge events are absent of negative surge, and the difference between the two cases is directly related to differences in the paths of the cyclones that cause the surge. These differences in cyclone paths are consistent with differences in the circulation poleward of the cyclones: for a long-duration surge, for at least half of the events there is a strong blocking event due north of the surge location, whereas, for a strong, short-duration surge event there is rarely blocking, and if there is blocking it is positioned to the northeast rather than due north.

The differences in the circulation patterns for short-duration and long-duration surge are worth emphasizing. In both cases there is notable anticyclonic flow downstream of the cyclone. For strong, short-duration surge, the anticyclone is part of a traveling wave packet, whereas, for long-duration surge the upper-level waves are breaking or possibly being guided east/southeast due to the poleward block. Based on the differences in these details, which are clear in both the case study (Fig. 5) and the composite (Fig. 6), one can propose that there is a continuum of cyclone track behavior related to the position of the poleward anticyclone and the relative size of the two circulation features. Furthermore, the long-duration events associated with strong poleward blocking could provide added amount of lead time in the predictability in the development of the large-scale flow preceding a long-duration surge event. By way of example, Fig. 11 demonstrates that strong anticyclonic anomalies develop well before the surge maximum for the long-duration surge events. 
Upper-level Composites for Boston, MA

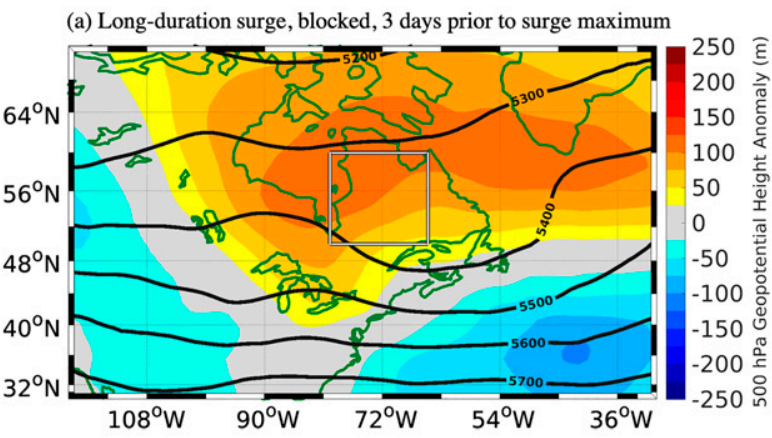

(b) Long-duration surge, not blocked, 3 days prior to surge maximum

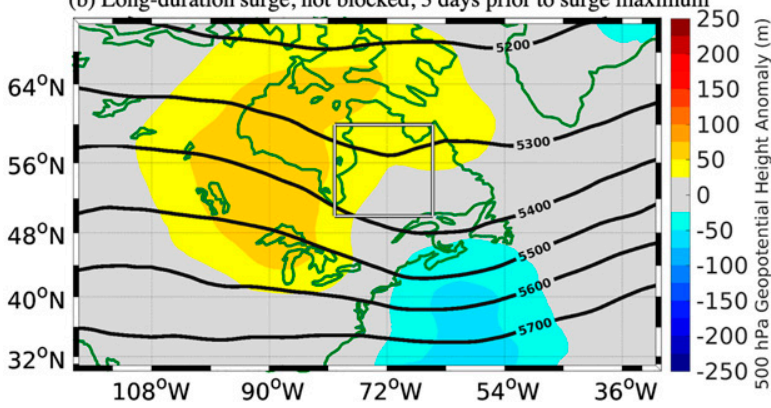

(c) Long-duration surge, blocked, date of surge maximum

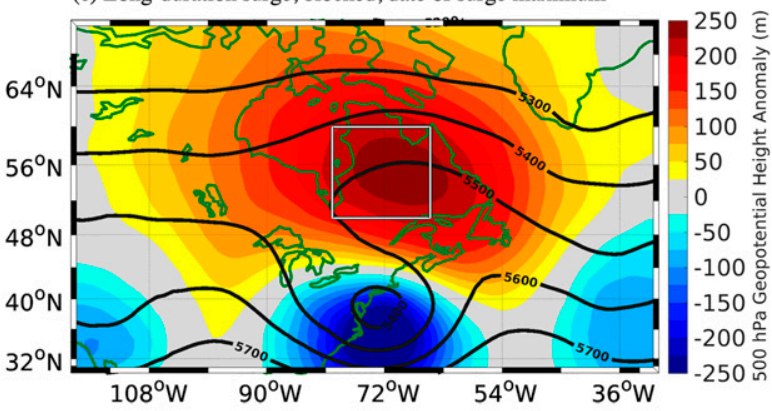

(d) Long-duration surge, not blocked, date of surge maximum

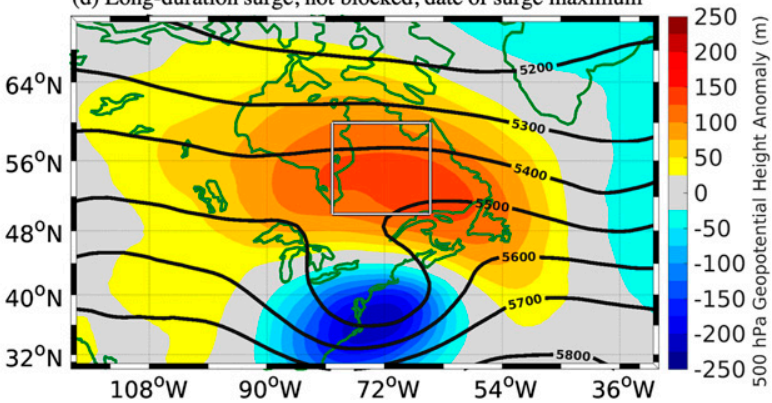

FIG. 11. Composites of the upper-level circulation for long-duration surge events at Boston. All plots show the 500-hPa geopotential height (contours) and anomalies (shading). Shown are (a),(b) the data 3 days prior to the surge maximum and (c), (d) the data at the date of the surge maximum for (top) Blocked long-duration surge cases and (bottom) not-blocked long-duration surge cases.

A comparison of surge duration and surge maximum for sites in the northeastern United States shows that these two metrics are correlated with one another. There are exceptions to this relationship, largely due to tropical cyclones, which tend to be shorter in duration, but greater in magnitude. The use of duration in the assessment of storm surge is a standard practice in the engineering consulting industry for assessing coastal risks. In the literature, however, to our knowledge, there has been much less emphasis on duration. Herein, we have defined a metric for duration that can be easily implemented and used in future analysis.

Overall, this analysis provides two important stories: it reveals how the time evolution of strong storm surge relates to patterns in the atmospheric circulation, and specifically, it shows that poleward atmospheric blocking, when it is anomalously strong, offers a high probability that a cyclone, if also sufficiently strong, will generate long-duration surge. The details revealed in this study with regard to characteristics of cyclones and blocks in conjunction with surge events of varying durations provide valuable information on how compound weather hazards can lead to either strong, short-duration or long-duration surge events.

Acknowledgments. We thank the three reviewers for their comments. This material is based upon work partially supported by the National Science Foundation under Grant 1854773. We thank Mike Bauer for sharing the tracking algorithm used for tracking cyclones and Etienne Dunn-Sigouin for sharing advice on implementing the block tracking algorithm. Author
Narinesingh was supported through NOAA Educational Partnership Program/Minority-Serving Institutions award number NA16SEC4810008 to the Center for Earth System Sciences and Remote Sensing Technologies (at CCNY, UPRM, UTEP, UMBC, or SDSU). Contents are solely the responsibility of the award recipient (Narinesingh) and may not represent official views of NOAA or the U.S. Department of Commerce.

Data availability statement. All of the water-level data used herein are available for download from NOAA and UHSL (http:// tidesandcurrents.noaa.gov and https://uhslc.soest.hawaii.edu/datainfo/, respectively). The atmospheric reanalysis data are available from the European Commission/Copernicus/ECMWF Climate Data Store (https://cds.climate.copernicus.eu/\#!/search?text=ERA5\& type $=$ dataset).

\section{REFERENCES}

Bauer, M., G. Tselioudis, and W. B. Rossow, 2016: A new climatology for investigating storm influences in and on the extratropics. J. Appl. Meteor. Climatol., 55, 1287-1303, https:// doi.org/10.1175/JAMC-D-15-0245.1.

Bernhardt, J. E., and A. T. DeGaetano, 2012: Meteorological factors affecting the speed of movement and related impacts of extratropical cyclones along the U.S. East Coast. Nat. Hazards, 61, 1463-1472, https://doi.org/10.1007/s11069-011-0078-0.

Booth, J. F., H. Rieder, and Y. Kushnir, 2016: Comparing hurricane and extratropical storm surge for the mid-Atlantic and northeast coast of the United States for 1979-2013. Environ. 
Res. Lett., 11, 094004, https://doi.org/10.1088/1748-9326/11/9/ 094004.

—, E. Dunn-Sigouin, and S. Pfahl, 2017: The relationship between extratropical cyclone steering and blocking along the North American east coast. Geophys. Res. Lett., 44, 1197611984, https://doi.org/10.1002/2017GL075941.

Caldwell, P. C., M. A. Merrifield, and P. R. Thompson, 2015: Sea level measured by tide gauges from global oceans as part of the Joint Archive for Sea Level since 1846, version 5.5. NOAA/ National Centers for Environmental Information, accessed 15 May 2020, https://doi.org/10.7289/V5V40S7W.

Catalano, A. J., and A. J. Broccoli, 2018: Synoptic characteristics of surge-producing extratropical cyclones along the northeast coast of the United States. J. Appl. Meteor. Climatol., 57, 171184, https://doi.org/10.1175/JAMC-D-17-0123.1.

Catto, J. L., and A. Dowdy, 2021: Understanding compound hazards from a weather system perspective. Wea. Climate Extremes, 32, 100313, https://doi.org/10.1016/j.wace.2021.100313.

Colle, B. A., F. Buonaiuto, M. J. Bowman, R. E. Wilson, R. Flood, R. Hunter, A. Mintz, and D. Hill, 2008: New York City's vulnerability to coastal flooding. Bull. Amer. Meteor. Soc., 89, 829-842, https://doi.org/10.1175/2007BAMS2401.1.

__, K. Rojowsky, and F. Buonaito, 2010: New York City storm surges: Climatology and an analysis of the wind and cyclone evolution. J. Appl. Meteor. Climatol., 49, 85-100, https:// doi.org/10.1175/2009JAMC2189.1.

Copernicus Climate Change Service, 2017: ERA5: Fifth generation of ECMWF atmospheric reanalyses of the global climate. Copernicus Climate Change Service Climate Data Store, accessed 15 May 2020, https://cds.climate.copernicus.eu/cdsapp\#!/home.

Dee, D. P., and Coauthors, 2011: The ERA-Interim reanalysis: Configuration and performance of the data assimilation system. Quart. J. Roy. Meteor. Soc., 137, 553-597, https://doi.org/ 10.1002/qj.828.

Dunn-Sigouin, E., and S. Son, 2013: Northern Hemisphere blocking frequency and duration in the CMIP5 models. J. Geophys. Res. Atmos., 118, 1179-1188, https://doi.org/10.1002/jgrd.50143.

Gurumurthy, P., P. Orton, S. Talke, N. Georgas, and J. F. Booth, 2019: Mechanics and historical evolution of sea level blowouts in New York Harbor. J. Mar. Sci. Eng., 7, 160, https://doi.org/ 10.3390/jmse7050160.

Hague, B. S., and A. J. Taylor, 2021: Tide-only inundation: A metric to quantify the contribution of tides to coastal inundation under sea-level rise. Nat. Hazards, 107, 675-695, https:// doi.org/10.1007/s11069-021-04600-4.

Hersbach, H., C. Peubey, A. Simmons, P. Berrisford, P. Poli, and D. Dee, 2015: ERA-20CM: A twentieth-century atmospheric model ensemble. Quart. J. Roy. Meteor. Soc., 141, 2350-2375, https://doi.org/10.1002/qj.2528.

Holton, J. R., and G. J. Hakim, 2013: An Introduction to Dynamic Meteorology. 5th ed. Elsevier, $532 \mathrm{pp}$.

Landsea, C. W., and J. L. Franklin, 2013: Atlantic hurricane database uncertainty and presentation of a new database format. Mon. Wea. Rev., 141, 3576-3592, https://doi.org/ 10.1175/MWR-D-12-00254.1.
Lenggenhager, S., and O. Martius, 2019: Atmospheric blocks modulate the odds of heavy precipitation events in Europe. Climate Dyn., 53, 4155-4171, https://doi.org/10.1007/s00382019-04779-0.

Munroe, R., B. Montz, and S. Curtis, 2018: Getting more out of storm surge forecasts: Emergency support personnel needs in North Carolina. Wea. Climate Soc., 10, 813-820, https:// doi.org/10.1175/WCAS-D-17-0074.1.

NOAA, 2021: U.S. billion-dollar weather and climate disasters. Accessed March 2021, https://www.ncdc.noaa.gov/billions/.

Orton, P. M., T. M. Hall, S. Talke, A. F. Blumberg, N. Georgas, and S. Vinogradov, 2016: A validated tropical-extratropical flood hazard assessment for New York Harbor. J. Geophys. Res. Oceans, 121, 8904-8929, https://doi.org/10.1002/2016JC011679.

Pfahl, S., and H. Wernli, 2012: Quantifying the relevance of atmospheric blocking for co-located temperature extremes in the Northern Hemisphere on (sub-)daily time scales. Geophys. Res. Lett., 39, L12807, https://doi.org/10.1029/2012GL052261.

Rappaport, E. N., 2014: Fatalities in the United States from Atlantic tropical cyclones: New data and interpretation. Bull. Amer. Meteor. Soc., 95, 341-346, https://doi.org/ 10.1175/BAMS-D-12-00074.1.

Rex, D. F., 1950: Blocking action in the middle troposphere and its effect upon regional climate. Tellus, 2, 196-211, https:// doi.org/10.1111/j.2153-3490.1950.tb00331.x.

Roberts, K. J., B. A. Colle, N. Georgas, and S. Munch, 2015: A regression-based approach for cool-season storm surge predictions along the New York-New Jersey coast. J. Appl. Meteor. Climatol., 54, 1773-1791, https://doi.org/10.1175/ JAMC-D-14-0314.1.

Shimkus, C., M. Ting, J. F. Booth, S. B. Adamo, M. Madajewicz, Y. Kushnir, and H. E. Rieder, 2017: Winter storm intensity, hazards and property losses in the New York tristate area. Ann. N. Y. Acad. Sci., 1400, 65-80, https://doi.org/10.1111/ nyas.13396.

Sousa, P. M., R. M. Trigo, D. Barriopedro, P. M. M. Soares, A. M. Ramos, and M. L. R. Liberato, 2017: Responses of European precipitation distributions and regimes to different blocking locations. Climate Dyn., 48, 1141-1160, https://doi.org/10.1007/ s00382-016-3132-5.

Wahl, T., S. Jain, J. Bender, S. D. Meyers, and M. E. Luther, 2015: Increasing risk of compound flooding from storm surge and rainfall for major US cities. Nat. Climate Change, 5, 10931097, https://doi.org/10.1038/nclimate2736.

Warner, J. C., B. Armstrong, C. S. Sylvester, G. Voulgaris, T. Nelson, W. C. Schwab, and J. F. Denny, 2012: Storm-induced inner-continental shelf circulation and sediment transport: Long Bay, South Carolina. Cont. Shelf Res., 42, 51-63, https://doi.org/10.1016/j.csr.2012.05.001.

Zhang, K. Q., B. C. Douglas, and S. P. Leatherman, 2000: Twentieth-century storm activity along the U.S. east coast. J. Climate, 13, 1748-1761, https://doi.org/10.1175/15200442(2000)013<1748:TCSAAT > 2.0.CO;2.

Zscheischler, J., and Coauthors, 2018: Future climate risk from compound events. Nat. Climate Change, 8, 469-477, https:// doi.org/10.1038/s41558-018-0156-3. 